\title{
Chlorophyll as a Simple, Inexpensive and Environment-friendly Colorimetric Indicator for $\mathrm{NO}_{2}$ Gas
}

\author{
MAY KRISTINE O. BERNARDO and VOLTAIRE G. ORGANO* \\ Department of Physical Sciences and Mathematics, College of Arts and Sciences, \\ University of the Philippines, Manila 1000 Philippines. \\ *Corresponding author E-mail: vgorgano@ post.upm.edu.ph \\ http://dx.doi.org/10.13005/ojc/300206
}

(Received: April 15, 2014; Accepted: May 20, 2014)

\begin{abstract}
Chlorophyll is utilized as a simple, inexpensive and environment-friendly ("green") colorimetric indicator for nitrogen dioxide $\left(\mathrm{NO}_{2}\right)$ gas. A drastic color change from green to yellow was observed when chlorophyll, either dissolved in $\mathrm{CH}_{2} \mathrm{Cl}_{2}$ solution or absorbed into paper, was exposed to $\mathrm{NO}_{2}$ gas. Other gases such as $\mathrm{CO}_{2}$ and $\mathrm{SO}_{2}$ did not exhibit any color change with chlorophyll. Spectroscopic analysis showed nitration of chlorophyll as possible cause for the color change.
\end{abstract}

Key words: Chlorophyll, Colorimetric, Indicator, Sensing, Nitrogen dioxide, Test strips.

\section{INTRODUCTION}

Nitrogen dioxide $\left(\mathrm{NO}_{2}\right)$ is one of the prevalent oxide species of nitrogen in the atmosphere collectively known as $\mathrm{NO}_{x}$. It is characterized by a reddish-brown color with a pungent irritating odor. This pollutant gas is produced from combustion of fossil fuels and industrial processes. It is also a component of photochemical smog and responsible for production of acid rain. Its accumulation poses a threat to the environment because $\mathrm{NO}_{2}$ is highly reactive, corrosive and oxidative, causing discoloration and degradation of plant species. ${ }^{1}$ Its presence in the troposphere can also lead to various health issues. At low concentrations, $\mathrm{NO}_{2}$ can induce cough, nasal and eye irritations. At higher concentrations, it can lead to serious respiratory infections. ${ }^{2}$ These environmental and health concerns due to extensive circulation of $\mathrm{NO}_{2} /$ $\mathrm{NO}_{x}$ in the atmosphere necessitates development of novel approaches for its detection and monitoring.

In the last decade, many studies have been devoted to selectively monitor the levels of $\mathrm{NO}_{2}$ in the atmosphere. These include metallic oxides, ${ }^{3-6}$ organic semiconductors, ${ }^{7-9}$ metal complexes, ${ }^{10,11}$ and cage-like molecules. ${ }^{12-17}$ These approaches however require expensive materials and lengthy procedures for its synthesis. Here, we report a very simple and cheap approach towards sensing of 
$\mathrm{NO}_{2}$ gas by using a common pigment naturally occurring in plants: chlorophyll.

Chlorophyll is a metalloporphyrin pigment responsible for the green color of plants. It plays a major role in photosynthesis. However, chlorophyll is greatly affected by pollutant gases. Chapados and co-workers have observed that chlorophyll reacts with gases such as $\mathrm{SO}_{2}, \mathrm{H}_{2} \mathrm{~S}, \mathrm{NO}$ and $\mathrm{NO}_{2},{ }^{18}$ while Guidi et al noted that it can interact with ozone. ${ }^{19}$ Bevilaqua and co-workers also suggested that chlorophyll can potentially bind $\mathrm{CO}_{2}$ gas based on density functional calculations. ${ }^{20}$ These studies provide possibilities for chlorophyll as gas sensor. However, application of this natural pigment for naked-eye detection of pollutant gases has not been explored.

\section{EXPERIMENTAL}

All reagents and chemicals used were analytical grade and purchased from commercial sources. Solvents were used without any purification.

\section{Extraction of chlorophyll}

$100 \mathrm{~g}$ of cogon grass (Imperata cylindrica) was grinded and macerated for 3-5 min. in ethyl acetate. The crude sample was filtered, placed in a shaker for $5 \mathrm{~min}$ then left overnight at room temperature. The extract was rotavaped to a final volume of $200 \mathrm{~mL}$ and carefully decanted into an evaporated dish to exclude any undissolved matter. The extract was then heated to dryness in a water bath at $40^{\circ} \mathrm{C}$. The residue was purified using column chromatography $(30 \mathrm{~g}$ of silica gel with ethyl acetate). The first eluate which was yellow in color was discarded. Methanol was then used to elute the purified extract. The eluate was air dried, resulting to a dark green solid product $(0.0395 \mathrm{~g})$. The green product was dissolved with $\mathrm{CH}_{2} \mathrm{Cl}_{2}$ and used throughout the experiment.

\section{Production of gases}

Sulfur dioxide $\left(\mathrm{SO}_{2}\right)$ was prepared by adding 10 drops of $2 \mathrm{M} \mathrm{HCl}$ to $0.1 \mathrm{~g} \mathrm{NaHSO}_{3}$ in a test tube. Nitrogen dioxide $\left(\mathrm{NO}_{2}\right)$ was prepared by reacting a small piece of copper metal with concentrated $\mathrm{HNO}_{3}$. Carbon dioxide $\left(\mathrm{CO}_{2}\right)$ was produced by reacting $0.1 \mathrm{~g} \mathrm{CaCO}_{3}$ with 10 drops of
$5 \mathrm{M} \mathrm{HCl}$. The gases were introduced into $3.0 \mathrm{~mL}$ chlorophyll solutions via a $5-\mathrm{mL}$ syringe.

\section{Titration of chlorophyll solution}

$\mathrm{NO}_{2}-\mathrm{CH}_{2} \mathrm{Cl}_{2}$ solution was prepared by carefully bubbling $\mathrm{NO}_{2}$ gas to dry $\mathrm{CH}_{2} \mathrm{Cl}_{2}$. Concentration of $\mathrm{NO}_{2}$ was determined according to published procedure. ${ }^{21} 0-900 \mathrm{~mL}$ of $\mathrm{NO}_{2}-\mathrm{CH}_{2} \mathrm{Cl}_{2}$ solution was used in the titration.

\section{Gas detection using test strips}

Filter paper strips $(5 \mathrm{~cm} \times 1.5 \mathrm{~cm})$ were soaked in a $5-\mathrm{ml}$ chlorophyll- $\mathrm{CH}_{2} \mathrm{Cl}_{2}$ solution until dark green strips were formed. Strips were air dried, transferred in a vial and covered. Gas was introduced into each vial using a syringe.

\section{Spectral analysis}

Spectral scans of untreated and gastreated chlorophyll solutions in $\mathrm{CH}_{2} \mathrm{Cl}_{2}$ were recorded on a Shimadzu 1700 spectrometer from 300-800 nm. Infrared spectra were recorded on a $\mathrm{KBr}$ pellet and analyzed using a Perkin-Elmer 1600 series Fourier Transform Spectrophotometer.

\section{RESULTS AND DISCUSSION}

Chlorophyll, a green pigment in plants, was investigated for its potential use as colorimetric indicator for $\mathrm{NO}_{2}$. Chlorophyll was extracted from cogon grass using ethyl acetate, purified using column chromatography, and then dried. The $\mathrm{CH}_{2} \mathrm{Cl}_{2}$ solution of chlorophyll was placed in a sealed vial and bubbled with $\mathrm{NO}_{2}$ gas. This resulted to a drastic color change of the chlorophyll solution from green to yellowish-brown (Fig. 1). Other gases such as $\mathrm{CO}_{2}$ and $\mathrm{SO}_{2}$ did not exhibit any color change. Previous studies have shown that $\mathrm{CO}_{2}$ has no effect on the structure of chlorophyll, while $\mathrm{SO}_{2}$ gas does not react with chlorophyll in the absence of water. ${ }^{18,22}$

Visible spectra of chlorophyll exposed to $\mathrm{NO}_{2}$ show prominent bands that are distinct from the bands observed in chlorophyll alone (Fig. 2A). Absorption bands with $\lambda_{\text {max }}$ at $414 \mathrm{~nm}$ and $666 \mathrm{~nm}$ shifted to $424 \mathrm{~nm}$ and $679 \mathrm{~nm}$, respectively. The band around 470-480 $\mathrm{nm}$ also disappeared upon addition of $\mathrm{NO}_{2}$. These spectral changes are consistent with a study conducted by Chapados et 


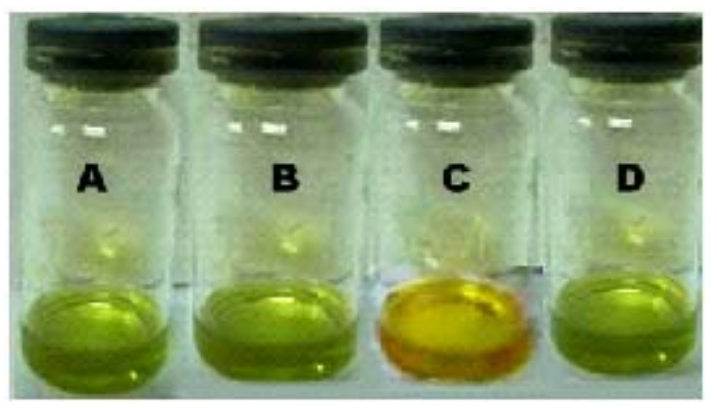

Fig. 1: Visual detection of gas samples in solution. A) chlorophyll solution in $\mathrm{CH}_{2} \mathrm{Cl}_{2}, \mathrm{~B}$ ) chlorophyll solution after exposure to $\mathrm{CO}_{2}, \mathrm{C}$ ) chlorophyll solution after exposure to $\mathrm{NO}_{2}, \mathrm{D}$ ) chlorophyll solution after exposure to $\mathrm{SO}_{2}$

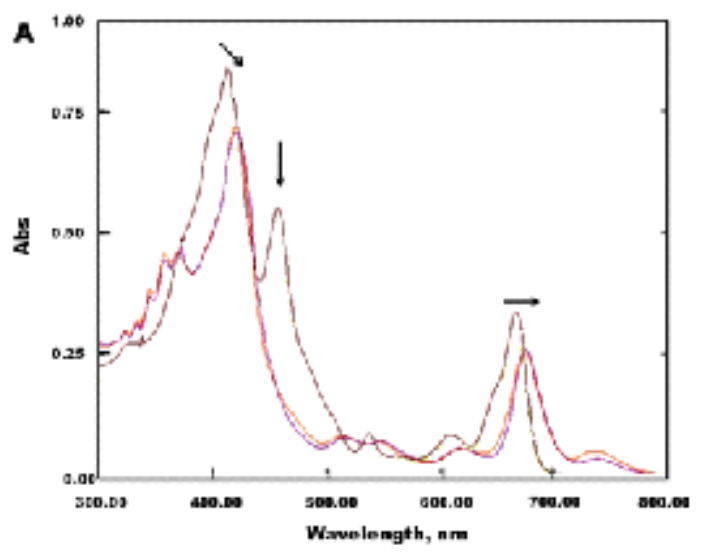

al. showing the effect of $\mathrm{NO}_{2}$ gas on chlorophyll a multilayer $^{18}$

The same spectral change was recorded when chlorophyll was titrated slowly with $\mathrm{NO}_{2}-$ $\mathrm{CH}_{2} \mathrm{Cl}_{2}$ solution (Fig. 2B). It was also noted that the chlorophyll solution was able to detect $\mathrm{NO}_{2}$ with concentrations greater than $2 \mathrm{mM}$ in $\mathrm{CH}_{2} \mathrm{Cl}_{2}$ solution (Fig. 2B insert). Similar titration experiments have been conducted by Rudkevich et al. on calixarenes with $\mathrm{NO}_{2}-\mathrm{CH}_{2} \mathrm{Cl}_{2}$ solution to estimate limit of detection for $\mathrm{NO}_{2}{ }^{16}$

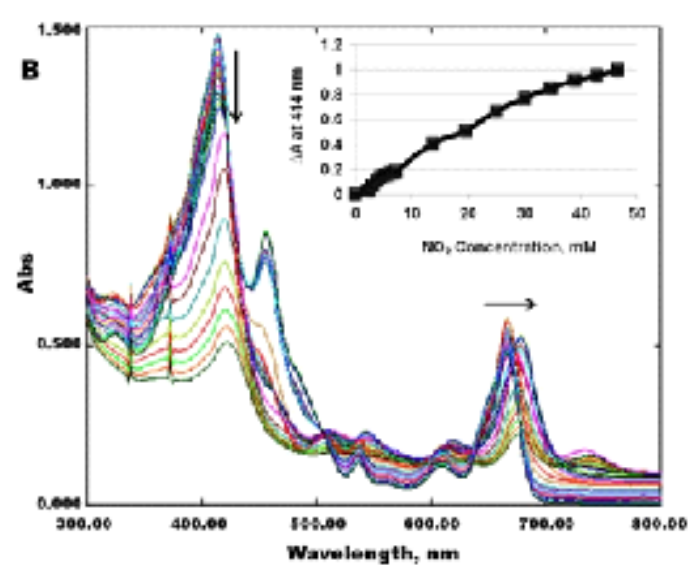

Fig. 2(A): UV-Vis spectra of chlorophyll bubbled with $\mathrm{NO}_{2}$ gas. (B) UV-Vis titration of chlorophyll with $\mathrm{NO}_{2}-\mathrm{CH}_{2} \mathrm{Cl}_{2}$ solution. Insert: Plot of change in absorbance at $414 \mathrm{~nm}$ versus $\mathrm{NO}_{2}$ concentration

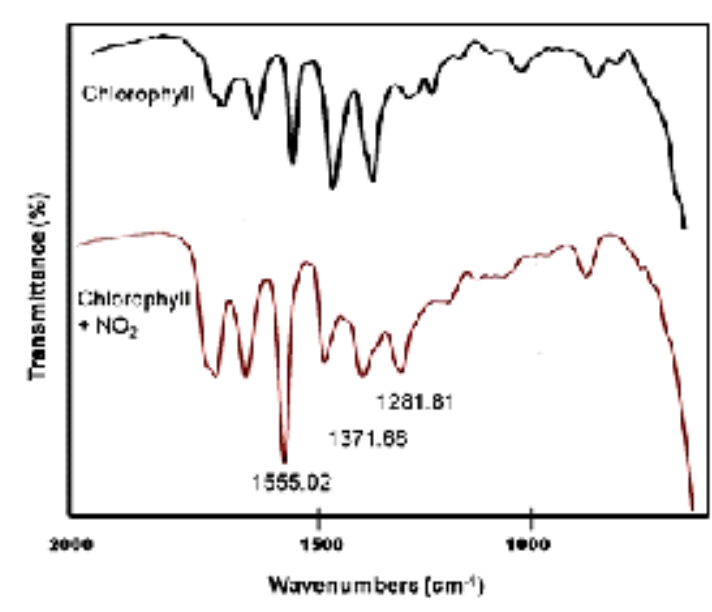

Fig. 3: Portion of FTIR spectra of chlorophyll before and after $\mathrm{NO}_{2}$ exposure

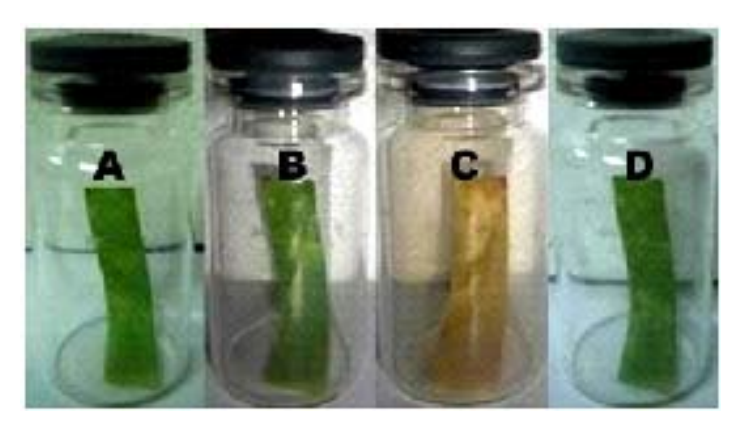

Fig. 4: Gas detection using test strips. A) Test strip with chlorophyll alone, B) Test strip after exposure to $\mathrm{CO}_{2}, \mathrm{C}$ ) Test strip after exposure to $\mathrm{NO}_{2}$, D) Test strip after exposure $\mathrm{SO}_{2}$ 
Additionally, bubbling oxygen gas into the $\mathrm{NO}_{2}$-treated chlorophyll solution did not change the spectra. This suggests that there is a strong interaction or irreversible reaction that took place between chlorophyll and $\mathrm{NO}_{2}$ gas. Thin layer chromatography of the product formed from the reaction of chlorophyll and $\mathrm{NO}_{2}$ suggests a complete transformation of chlorophyll into a new compound, possibly a nitrated product. This was confirmed by FTIR spectroscopy where distinct bands were detected at $1555 \mathrm{~cm}^{-1}$ and $1372 \mathrm{~cm}^{-1}$ characteristic of an $-\mathrm{NO}_{2}$ group (Fig. 3). Another band at $1282 \mathrm{~cm}^{-1}$ which was not present at the spectrum of chlorophyll solution may be due to formation of an $\mathrm{N}-\mathrm{NO}_{2}$ group. ${ }^{23}$ This result suggests that nitration occurred when chlorophyll was exposed to $\mathrm{NO}_{2}$. Nitration reactions are known to occur in porphyrin complexes caused by $\mathrm{NO}_{2}$ gas. ${ }^{24}$

Interaction between gases and chlorophyll was also studied in solid state using test strips. Figure 4 shows green coloration of filter paper after soaking it in chlorophyll solution. When the dried test strip was exposed to $\mathrm{NO}_{2}$, the color turned from green to yellow-brown, similar to the color change observed in solution. No color change was noted when test strips were exposed to $\mathrm{CO}_{2}$ and $\mathrm{SO}_{2}$. This observation clearly indicates the selectivity of chlorophyll towards $\mathrm{NO}_{2}$ gas. The study also demonstrates as proof-of-principle the potential use of chlorophyll-based sensors for naked-eye detection of $\mathrm{NO}_{2}$ gas.

\section{CONCLUSION}

In conclusion, a simple and cheap colorimetric indicator for $\mathrm{NO}_{2}$ gas based on chlorophyll was developed. This pigment can be obtained easily from plant materials and be used either in solution or as test strips.

Moreover, the method presented here is inexpensive since gases can be produced from common laboratory reagents, and the set-up requires minimal use of equipment. Thus, this method can be performed in the classroom to demonstrate not only the sensitivity of chlorophyll towards $\mathrm{NO}_{2}$ but also the destructive effect of $\mathrm{NO}_{2}$ gas to chlorophyll pigment of plants. Further work will be directed towards improving the detection limit and applying it as $\mathrm{NO}_{2}$ sensor for environmental monitoring.

\section{ACKNOWLEDGMENTS}

Financial support was provided by the Creative Work and Research Grant (CWRG Grant No. 2012-25) of the University of the Philippines System.

\section{REFERENCES}

1. U. S. Environmental Protection Agency, http:/ /www.epa.gov/iaq/no2.html (Accessed December 2013).

2. Romieu, I.; Moreno-Macias, H.; London, S. J. Proc. Am. Thorac. Soc. 2010, 7, 116-122

3. Chougule, M. A.; Sen, S.; Patil, V. B. Ceram. Int. 2012, 38, 2685-2692

4. Afzal, A.; Cioffi, N.; Sabbatini, L.; Torsi, L. Sens. Actuators B: Chem. 2012, 171-172, 25-42

5. Kaur, J.; Roy, S. C.; Bhatnagar, M. C. Sens. Actuators B: Chem. 2007, 123, 1090-1095

6. Tan, J.; Wlodarski, W.; Kalantarzadeh, K. Thin Solid Films 2007, 515, 8738-8743

7. Valentini, L.; Armentano, I.; Kenny, J. M.; Cantalini, C.; Lozzi, L.; Santucci, S. Appl. Phys. Lett. 2003, 82, 961-963

8. Christensen, W. H.; Sinha, D. N.; Agnew, S. F.
Sens. Actuators B: Chem. 1993, 10, 149-153

9. Das, A.; Dost, R.; Richardson, T.; Grell, M.; Morrison, J. J.; Turner, M. L. Adv. Mater. 2007, 19, 4018-4023

10. Pochekailov, S.; Nozar, J.; Nešporek, S.; Rakušan, J.; Karásková, M. Sens. Actuators B: Chem. 2012, 169, 1-9

11. Shu, J. H.; Wikle III, H. C.; Chin, B. A. ECS Trans. 2010, 33, 131-140

12. Kang, Y.; Zyryanov, G. V.; Rudkevich, D. M. Chem. Eur. J. 2005, 11, $1924-1932$

13. Rudkevich, D. M. Eur. J. Org. Chem. 2007, 20, 3255-3270

14. Hines, J. H.; Wanigasekara, E.; Rudkevich, D. M.; Rogers, R. D. J. Mater. Chem. 2008, 18, 4050-4055

15. Organo, V. G.; Sgarlata, V.; Firouzbakht, F.; 
Rudkevich, D. M. Chem. Eur. J. 2007, 13, 4014-4023

16. Kang, Y.; Rudkevich, D. M. Tetrahedron, 2004, 60, 11219-11225

17. Ohira, S.-I.; Wanigasekara, E.; Rudkevich, D. M.; Dasgupta, P. K. Talanta 2009, 77, 18141820

18. Chapados, C.; Germain, D.; Leblanc, R. M. Can. J. Chem. 1981, 59, 2402-2411

19. Guidi, L.; Nali, C.; Ciompi, S.; Lorenzini, G.; Soldatini, G. F. J. Exp. Bot. 1997, 48, 173-179

20. Bevilaqua, R. C. A.; Zanella, I.; Fagan, S. B. Chem. Phys. Lett. 2010, 496, 310-315
21. Fanning, J. C.; Mandel, F. S.; Gray, T. L.; DattaGupta, N. Tetrahedron 1979, 35, 1251-1255

22. Chapados, C.; Germain, D.; Leblanc, R. M. Biophys. Chem. 1980, 12, 189-198

23. Lin-Vien D., Colthup N. B., Fateley W. G., and Grassell J. G., The Handbook of Infrared and Raman Characteristic Frequencies of Organic Molecules, Academic Press, San Diego, CA 1991.

24. Catalano, M. M.; Crossley, M. J.; Harding, M. M.; King, L. G. J. Chem. Soc., Chem. Commun. 1984, 1535-1536. 